\title{
HISTÓRIA DA MATEMÁTICA E ATIVIDADES COM O TEODOLITO: CONTRIBUIÇÕES DO PIBID/UVA PARA APRENDIZAGEM DA TRIGONOMETRIA
}

\section{HISTORYOF MATHEMATICS AND ACTIVITIES WITH THEODOLITE: CONTRIBUTIONS OF PIBID/UVA FOR TRIGONOMETRY LEARNING}

\author{
Maria Mailâne Vieira da Silva ${ }^{1}$ \\ Universidade Estadual Vale do Acaraú \\ Deisiane Linhares Lima ${ }^{2}$ \\ Universidade Estadual Vale do Acaraú \\ Maria José Araújo Souza \\ Universidade Estadual Vale do Acaraú
}

\section{Resumo}

O objetivo deste trabalho é relatar uma atividade realizada com estudantes do $3^{\circ}$ ano do Ensino Médio, em uma escola pública no interior do Ceará, utilizando-se do ensino de Trigonometria e fazendo uma mediação com seus fatos históricos que resultaram no desenvolvimento desse campo da Matemática. $\mathrm{O}$ trabalho foi realizado no âmbito do Subprojeto de Matemática do Programa Institucional de Bolsas de Iniciação à Docência (PIBID) da Universidade Estadual Vale do Acaraú (UVA) e buscou promover a construção de conhecimentos vinculados à Trigonometria, analisando as possibilidades de se inserir a História da Matemática no ensino dessa, a fim de sanar as dificuldades encontradas pelos discentes. Viu-se que essa veiculação pode se dar de várias formas, inclusive com atividades diferenciadas integrando a Matemática com as demais disciplinas, ou seja, fazendo-se uso da interdisciplinaridade, para dessa forma, colaborar com uma aprendizagem mais eficaz. Os estudantes foram encorajados a pesquisar, a explorar e interpretar conceitos Trigonométricos, principalmente por meio de atividades práticas, o que potencializa a assimilação desses conteúdos. Durante as atividades ocorreu à construção de um teodolito, instrumento usado na medição de distâncias inacessíveis, neste caso, utilizado para medir a altura da caixa d'água da escola em questão. Com a aplicação das atividades, os discentes mostraram maior interesse e aceitação pela Trigonometria, uma vez que a História da Matemática e a utilização de materiais manipuláveis tornaram o processo de ensino e aprendizagem mais interativo, construtivo e participativo, contribuindo assim, para desmistificar a ideia de que a Matemática é inatingível evidenciando sua utilização no dia a dia.

Palavras-chave: História da Matemática; Trigonometria; Educação Matemática.

\footnotetext{
Abstract

${ }^{1}$ E-mail: maylannesilva.12@gmail.com.

${ }^{2}$ E-mail: deyse1515@gmail.com.

${ }^{3}$ E-mail: mazesobral@yahoo.com.br.
} 
The objective of this work is to describe an activity carried out with students of the 3rd year of High School, in a public school in the interior of Ceará, using the teaching of Trigonometry and mediating with their historical facts that resulted in the development of this field of Mathematics. The work was carried out within the framework of the Mathematics Subproject of the Institutional Scholarship Program (PIBID) of the Vale do Acaraú State University (UVA) and sought to promote the construction of knowledge linked to Trigonometry, analyzing the possibilities of inserting History of Mathematics in its teaching, in order to remedy the difficulties encountered by the students. It has been seen that this can take place in several ways, including with differentiated activities integrating Mathematics with the other disciplines, that is, making use of interdisciplinarity, in order to collaborate with a more effective learning. Students were encouraged to research, explore and interpret Trigonometric concepts, mainly through practical activities, which potentiates the assimilation of these contents. During the activities the construction of a theodolite, an instrument used in the measurement of inaccessible distances, in this case, was used to measure the height of the water box of the school in question. With the application of the activities, the students showed greater interest and acceptance by Trigonometry, since the History of Mathematics and the use of manipulative materials made the process of teaching and learning more interactive, constructive and participative, thus contributing to demystify the idea That the Mathematics is unattainable evidencing its use in the day to day.

Keywords: History of Mathematics; Trigonometry; Mathematics Education.

\section{Introdução}

Muitas dificuldades são encontradas no processo de ensino e aprendizagem de Matemática no que diz respeito aos seus conteúdos conceituais e as suas aplicações, em especial, o ensino da Trigonometria, como reforçado por Bortoli (2012, p.15) o qual destaca que "[...] muitos estudantes têm dificuldades em aprender os conceitos de Trigonometria, revertendo os resultados negativos gerados pela simples memorização de fórmulas". Assim, buscando estratégias para mudar essa realidade, como parte das atividades do Subprojeto de Matemática do Programa Institucional de Bolsas de Iniciação à Docência (PIBID) da Universidade Estadual Vale do Acaraú (UVA), desenvolveu-se uma atividade sobre a utilização dos fatos da História da Matemática como auxílio no ensino de Trigonometria no Ensino Médio.

Promoveu-se, junto a um grupo de estudantes do $3^{\circ}$ ano da Escola de Ensino Médio Monsenhor Linhares - escola parceira do PIBID/UVA, localizada no município de Groaíras - CE, distante $24 \mathrm{~km}$ de Sobral (sede da UVA) - a construção de

conhecimentos vinculados à Trigonometria, a fim de analisar as possibilidades de se inserir a História da Matemática no ensino de Trigonometria, para ajudar a sanar 
dificuldades que alguns discentes apresentam e mostrar a utilidade desses conteúdos em situações práticas.

Dessa forma, buscou-se como ponto central para este projeto, a construção dos conhecimentos Trigonométricos aliados aos fatos da História da Matemática, possibilitando apresentar o como e o porquê do surgimento histórico dos temas abordados nas aulas, ajudando na produção dos conhecimentos estudados e na compreensão de suas aplicações no cotidiano.

\title{
Referencial Teórico
}

A História da Matemática é um instrumento ponderoso para explicar a origem dos vários axiomas, conceitos, fórmulas e postulados, tem o papel de situar o discente no tempo e no espaço, contextualizando o assunto estudado. A seriedade desse recurso no processo de ensino e aprendizagem da Matemática é abordada nos Parâmetros Curriculares Nacionais $(\mathrm{PCN})$,

\begin{abstract}
A História da Matemática pode oferecer uma importante contribuição ao processo de ensino e aprendizagem dessa área do conhecimento. Ao revelar a Matemática como uma criação humana, ao mostrar necessidades e preocupações de diferentes culturas, em diferentes momentos históricos, ao estabelecer comparações entre os conceitos e processos matemáticos do passado e do presente, o professor cria condições para que o aluno desenvolva atitudes e valores mais favoráveis diante desse conhecimento. Além disso, conceitos abordados em conexão com sua história constituem veículos de informação cultural, sociológica e antropológica de grande valor formativo. A História da Matemática é, nesse sentido, um instrumento de resgate da própria identidade cultural. (BRASIL, 1998, p. 42).
\end{abstract}

É primordial trabalhar com uma metodologia de ensino que leve em conta os aspectos históricos, pois se torna possível resgatar a realidade dos fatos e assim, formar indivíduos mais conscientes de acontecimentos passados, auxiliando-os na construção do conhecimento de conceitos matemáticos vistos atualmente, uma vez que esse recurso contribui para a motivação do aluno e auxilia na superação das dificuldades encontradas por eles. Assim, como é abordada por Miguel:

[...] o conhecimento histórico dos processos matemáticos despertaria o interesse do aluno pelo conteúdo que está sendo ensinado. Os mais ingênuos acabam atribuindo à história um poder quase mágico de modificar a atitude 
do aluno em relação à matemática. [...] o poder motivador da história é atestado e exaltado em função da adoção de uma concepção lúdica ou recreativa da mesma. $(1997$, p.3)

Além de Miguel, outros autores como Brito e Bayer, também afirmam o poder motivacional e as importantes contribuições da História da Matemática. Segundo eles:

[...] trabalhar a história constitui um fator que contribuiu para a motivação do aluno, despertando o interesse pelo conteúdo que está sendo ensinado, evidenciando a ligação entre os diferentes ramos do conhecimento e a razão da existência de determinados conteúdos. Não se trabalha somente o resultado, mas como se chega a ele, aí estamos fazendo história, ensinando Matemática, consequentemente fazendo Educação. (2007, p. 62)

Dessa forma, são perceptíveis as contribuições que a utilização da História da Matemática proporciona ao motivar o discente e mostrar o real sentido e o valor do estudo de Matemática. Essa abordagem pode se dar de várias formas como oportunidade de promover atividades diferenciadas integrando a Matemática com as demais disciplinas, como exemplo, fazendo-se uso da interdisciplinaridade, despertando nos discentes a autonomia e o interesse em aprender, permitindo, ainda, que os mesmos consigam enxergar que existem conexões entre o conhecimento matemático e as várias áreas de conhecimento.

Assim, a combinação entre a História da Matemática e a Trigonometria pode trazer importantes resultados que contribuem para um entendimento mais incisivo e com um menor teor de cálculos algébricos, como afirma Palarmido em seu estudo:

Os Parâmetros Curriculares Nacionais apontam para a necessidade de relacionar etapas da História da Matemática com a evolução da humanidade, e do estudo da Trigonometria estar ligado às suas aplicações, como evidenciar o cálculo de distâncias inacessíveis e a construção de modelos de fenômenos periódicos, amenizando os cálculos algébricos. (2008, p. 80)

Nesse sentido, lançando mão da História da Matemática como estratégia metodológica para o ensino da Matemática, em especial neste trabalho, a Trigonometria, a seguir são apresentados os procedimentos metodológicos.

\section{Procedimentos Metodológicos}


Essa pesquisa é de caráter qualitativo e buscou promover a construção de conhecimentos relacionados à Trigonometria analisando as possibilidades de se inserir a História da Matemática no ensino dessa.

Em relação ao método empregado nesse projeto, os dados foram coletados a partir de observações e de comentários (feitos pelos discentes) registrados através de anotações de campo, questionários e fotografias.

Considerando a importância da História da Matemática no ensino de Matemática, como citado acima, e visando despertar o interesse e a necessidade dos discentes pelos estudos de conteúdos relacionados à Trigonometria e a sua aplicabilidade, utilizaram-se estratégias que visava uma interação entre os discentes e o aprendizado de forma mais eficaz e próxima da realidade do mesmo. Dessa forma, o projeto apresentou para os estudantes uma breve revisão dos conceitos básicos de Trigonometria e de seu contexto histórico e ainda, mostrou-se uma das diversas formas em que a Trigonometria pode ser aplicada de forma prática.

Previamente, as autoras do projeto - bolsistas do Subprojeto de Matemática do PIBID/UVA atuantes na escola mencionada - solicitaram à professora de Matemática do $3^{\circ}$ ano A, turno da manhã, que indicasse alguns estudantes para participar da atividade. Foram indicados cinco jovens entre 16 e 18 anos. Inicialmente, ocorreu a apresentação do projeto para os discentes no dia 01 de setembro de 2016, mostrando as propostas a serem desenvolvidas com as suas devidas participações. Em seguida, fora aplicado um questionário de sondagem, com o objetivo de observar os conhecimentos anteriormente adquiridos pelos alunos sobre Trigonometria e a utilização da História da Matemática como recurso metodológico, com o uso de perguntas abertas, tais como: "Você gosta de Matemática?", “O que você conhece sobre Trigonometria?”, "Você já ouviu falar sobre História da Matemática?". Em suma, as indagações contidas no questionário se relacionavam com os conhecimentos em relação à História da Matemática e a Trigonometria, metodologias utilizadas nas aulas de Matemática e o que os mesmo esperavam da aplicação do projeto. Assim, o estudante poderia expressar sua opinião em relação à Trigonometria e a História da Matemática, fazendo com isso um levantamento de dados com o intuito de se obter um norte para as próximas ações do projeto. Com base nos dados coletados no questionário de sondagem, foi trabalhada a 
História da Matemática como estratégia metodológica no estudo dos conteúdos Trigonométricos.

Foram realizados mais dois encontros, ambos no mês de setembro do ano de 2016. Para o primeiro momento, no dia 09 de setembro, fora entregue para cada estudante uma apostila contendo fatos históricos e conceitos da Trigonometria, suas aplicações e propriedades, exercícios resolvidos e exercícios propostos, para que os jovens pudessem fixar melhor o assunto exposto. Cada discente resolveu uma das questões no quadro para os demais presentes, estimulando a participação dos mesmos nos encontros.

No último encontro, realizado no dia 29 de setembro, os discentes conheceram o teodolito e um pouco de sua história, para em seguida realizar a construção de outro artesanal sob a orientação das bolsistas, com o objetivo de utilizá-lo para a medição da altura da caixa d'água da escola.

Em resumo, para a realização do projeto, ocorreram três encontros. O primeiro, no dia 01 de setembro com duração de 50 minutos, para apresentação do projeto e aplicação do questionário de sondagem. Já os outros dois encontros foram realizados nos dias 09 e 29 de setembro e tiveram duração de 1 hora e 40 minutos cada.

Para essa parte prática, além do teodolito construído pelos alunos, foi utilizada fita métrica e calculadora científica. Cada estudante teve a oportunidade de utilizar esses materiais, de conhecer seu funcionamento e logo em seguida, se dividiram para conseguir calcular a altura da caixa d'água e auxiliar um ao outro. Um dos discentes, utilizando o teodolito, fez a mensura do ângulo formado entre o topo da caixa d'água e o plano horizontal paralelo ao solo, outros dois alunos utilizaram a fita métrica para medir a distância entre o instrumento utilizado na mensura do ângulo e a base da caixa d'água e a altura do mesmo, enquanto outro fez anotações necessárias para realizar os cálculos. Após a obtenção dos dados necessários, retornaram-se para a sala de aula onde cada aluno realizou os cálculos propostos.

Após a realização do cálculo de alturas inacessíveis, fora entregue aos discentes um desafio, um problema envolvendo uma situação prática, para analisar as habilidades dos alunos na resolução de questões semelhantes as que já haviam sido resolvidas anteriormente, proporcionando uma análise dos benefícios da aplicação do projeto. 
Ao final, os participantes expuseram oralmente suas impressões acerca da atividade realizada, conforme será exposto logo abaixo.

\section{Resultados e Discussões}

É de grande relevância a inserção da História da Matemática como recurso metodológico para o Ensino de Matemática, visto que a sua utilização potencialmente torna as aulas menos mecânicas e levam os estudantes a construírem conceitos matemáticos a partir de situações cotidianas, uma vez que a Matemática é criação humana e surgiu com o intuito de resolver os problemas diários encontrados por diferentes povos.

Isso permite ao discente entender que o conhecimento matemático é construído historicamente e em longo prazo. Os estudos da construção histórica dos conhecimentos matemáticos levam a uma maior compreensão da evolução dos conceitos enfatizando as dificuldades epistemológicas, inerentes ao conceito que está sendo trabalhado.

Como já mencionado, inicialmente fora explicado aos alunos como se daria o desenvolvimento do projeto e fora realizada a aplicação de um questionário de sondagem, que visara observar os conhecimentos já adquiridos pelos alunos sobre Trigonometria e a utilização da História da Matemática como recurso metodológico.

Visando preservar a identidade dos alunos envolvidos nessa investigação, foram atribuídos códigos para cada um deles, identificando-os como: A1, A2, A3, A4 e A5. Com relação ao participante A1 (figura 1), percebe-se o prazer em estudar a Matemática e o reconhecimento da importância desta ciência para compreensão das demais ciências e do mundo, enquanto o participante A2 (figura 2) observa-se um menor interesse, embora o gostar da disciplina também esteja presente. 
Maria Mailâne Vieira da Silva, Deisiane Linhares Lima e Maria José Araújo Souza

História da Matemática e atividades com o teodolito: contribuições do PIBID/UVA para aprendizagem da Trigonometria

Figura 1: Registro escrito do participante A1

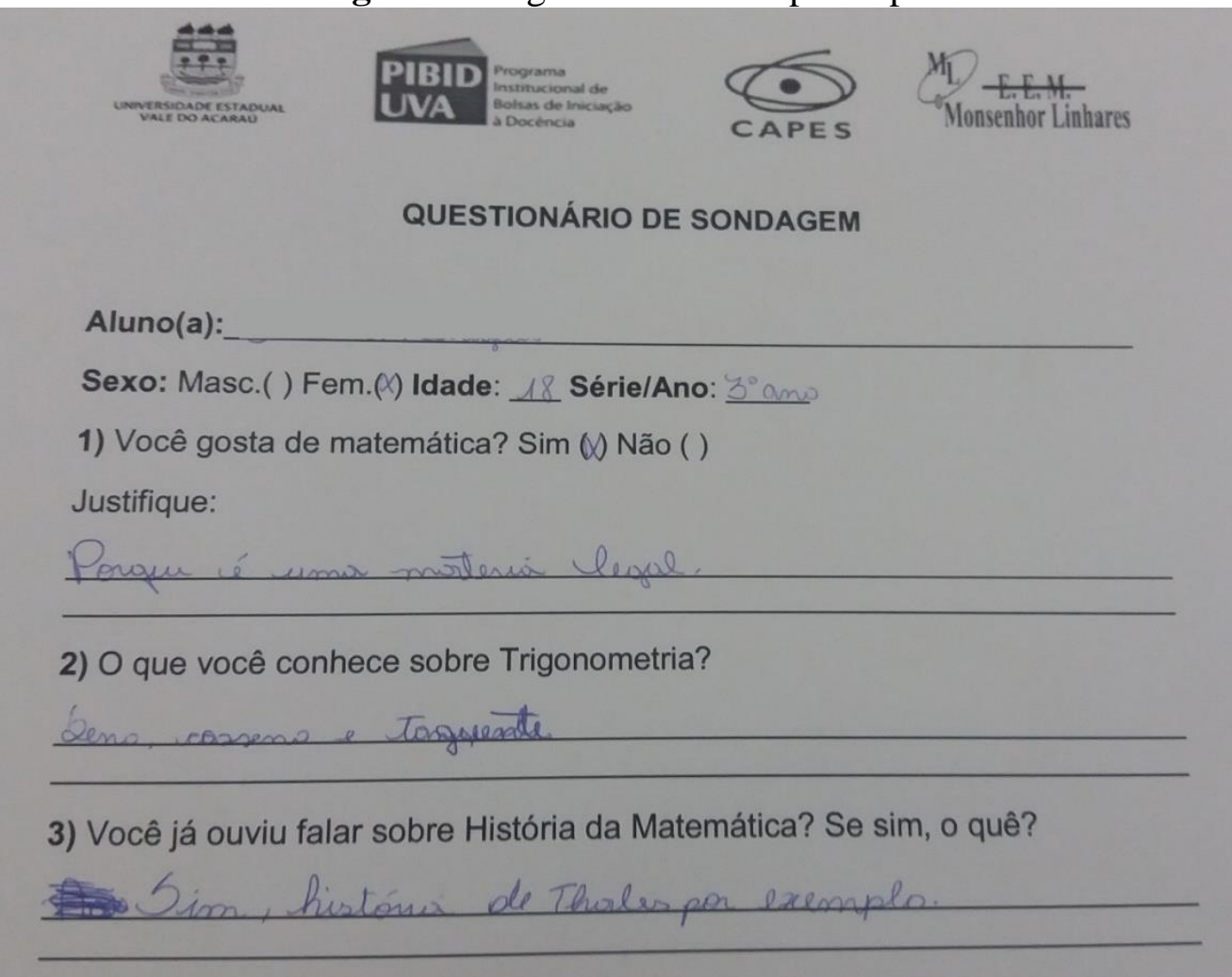

Fonte: Das próprias autoras

Figura 2: Registro escrito do participante A2

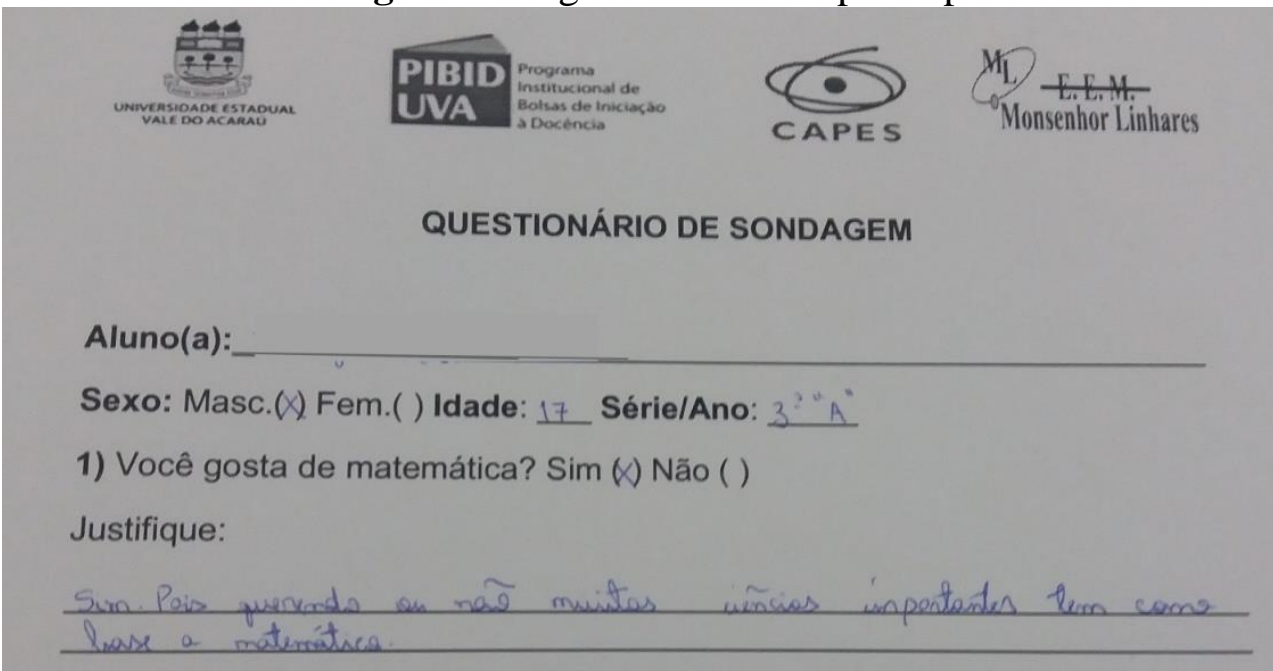

2) O que você conhece sobre Trigonometria?

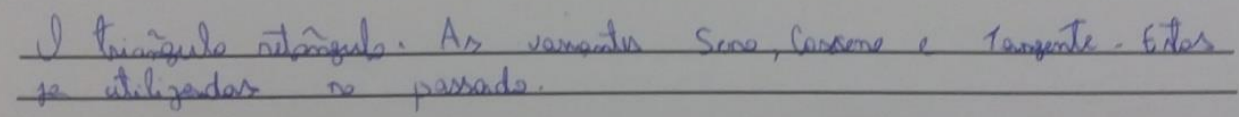

3) Você já ouviu falar sobre História da Matemática? Se sim, o quê?

Fonte: Das próprias autoras 
Ainda em relação a este questionário, foi possível perceber o pouco conhecimento em relação à História da Matemática pelos mesmos, evidenciando a pouca utilização pelos profissionais da educação desse importante recurso em sala de aula, como é possível perceber nas respostas ao item 3 do questionário (figuras 1 e 2). Observou-se ainda, nos comentários feitos pelos discentes no momento da resolução a mínima utilização da História da Matemática, "Nós já vimos alguma coisa de História da Matemática?”, "Vimos sim, lembra da história de Tales de Mileto?”, comentários como estes evidenciam a limitada utilização desse recurso e a visão que muitos alunos possuem de que a História da Matemática se dedica apenas ao estudo da vida dos matemáticos. Como se pode perceber também, na pesquisa realizada por Britto e Bayer (2007) com professores de Matemática das escolas públicas e privadas de Ensino Médio da $2^{\text {a }}$ CRE, com sede em São Leopoldo-RS, a qual mostra: “[...] que mais de 50\% dos professores não trabalham a História da Matemática, portanto, não utilizam este recurso nas suas atividades em sala de aula."

Mesmo com a pequena utilização da História da Matemática como recurso metodológico, seu emprego é bastante defendido por vários estudiosos e por aqueles que se utilizam dela. Ao pôr-se em prática esse projeto, constataram-se as extensas contribuições que a utilização da História da Matemática pode proporcionar no âmbito educacional, fato este percebido na fala dos alunos, com o interesse e melhor compreensão a partir do estudo de tais conteúdos fazendo-se uso da História da Matemática. Isso veio a corroborar com o defendido por Britto e Bayer (2007), os quais destacam que os professores que se utilizam desse recurso, afirmam que o mesmo torna a aula mais atrativa, auxiliando na compreensão dos assuntos estudados.

É a partir do contato com situação-problema, quer sejam materiais ou não, que os estudantes podem ampliar seu domínio cognitivo. Por isso, cabe-nos propor e testar estratégias que despertam a atenção dos alunos, trabalhando com exemplos práticos e concretos, sempre aproveitando seus conhecimentos prévios e partir da sua realidade construída. (MENDES, 2009, p.110)

Após a análise dos dados coletados através do questionário de sondagem, foi desenvolvida a apostila utilizada no primeiro encontro, tratando de assuntos básicos da Trigonometria e o contexto histórico que ocasionou seu surgimento, evidenciando dessa forma, a Matemática como criação humana utilizada para resolver situações do dia a 
dia, mostrando a tamanha importância dessa área do conhecimento, que muitas vezes não é reconhecida. A seguir, fora explicado aos discentes o conteúdo programado, fazendo uso da História da Matemática, mas especificamente da História da Trigonometria para esclarecer tais conceitos. Observou-se que os discentes não tiveram tantas dificuldades ao resolver os exercícios propostos, uma vez que os mesmos estavam mais motivados a buscar a solução dos problemas, visto que foi apresentada a Matemática com uma metodologia diferenciada, ao se fazer uso do contexto histórico, das situações cotidianas e das atividades práticas em que a Trigonometria está presente.

Para o último encontro, as bolsistas inicialmente apresentaram aos discentes um teodolito artesanal, do Laboratório de Ensino em Matemática (LEMA), construído pelos acadêmicos do curso de Licenciatura em Matemática da UVA, visto que esse instrumento óptico não era do conhecimento dos mesmos. Apresentou-se, também, o contexto histórico no qual ele foi desenvolvido e como se dá a sua utilização atualmente.

A partir disso, os discentes desenvolveram um teodolito artesanal (Figura 3), fazendo uso de materiais descartáveis e de baixo custo, que posteriormente fora utilizado pelos mesmos para a medição da altura da caixa d'água da escola (Figura 4).

Figura 3: Alunos construindo o teodolito

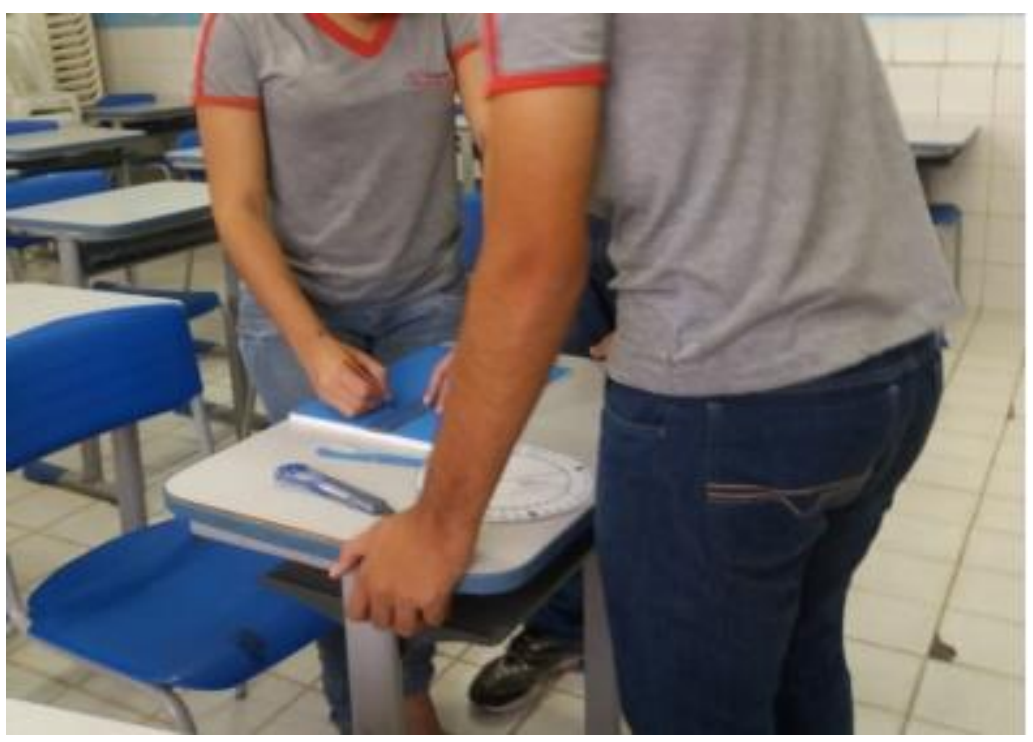

Fonte: Das próprias autoras 
Figura 4: Alunos utilizando o teodolito

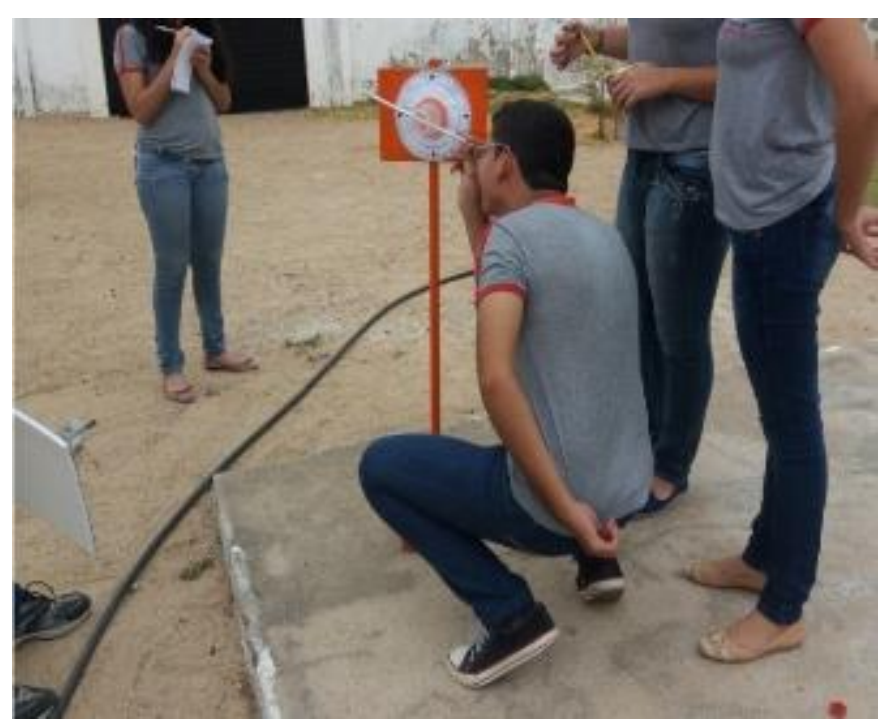

Fonte: Das próprias autoras

Os discentes participaram de forma ativa na construção e utilização do teodolito, na construção, por problemas com alguns materiais, não foi possível fixar o teodolito a uma base, dessa forma o teodolito construído pelos mesmos foi utilizado para conhecer o funcionamento desse instrumento. Para realizar o cálculo da altura da caixa d'água da escola em questão, visando cálculos mais precisos, foi utilizado o teodolito do Laboratório de Ensino em Matemática (LEMA). A obtenção dos dados e a realização do cálculo ocorreram de acordo com o planejado.

O desenvolvimento das atividades de forma diferenciada proporcionou aos alunos um maior interesse pela Trigonometria, despertando maior iniciativa, mais participação e espírito de pesquisa. Consequentemente, isso promoveu uma melhor compreensão acerca de um assunto de grande importância e que está sempre presente em provas externas, tais como Sistema Permanente de Avaliação da Educação Básico do Ceará (SPAECE)e Exame Nacional do Ensino Médio (ENEM) conforme pontua Justino (2013, p.108) “(...) mais interesse do aluno, estimulando assim sua participação nas aulas, tornando-as mais dinâmicas". Além disso, o uso de situações concretas pode auxiliar a compreensão e interpretação de fatos que surgem no meio social em que estão inseridos.

\section{Considerações Finais}


As dificuldades de aprendizagem em Matemática podem ocorrer por diversos fatores, entre eles pelo fato dos alunos não gostarem ou pelo nível de relativa complexidade. Dessa forma é imprescindível que o professor tenha uma preocupação maior com relação à metodologia utilizada. É importante que o método de ensino esteja adequado à realidade do aluno e que se busquem alternativas para desenvolver o cidadão de forma íntegra e participativa. No sentido de buscar melhorias para o ensino de Matemática, foram observadas as importantes contribuições que a História da Matemática pode trazer como estratégia metodológica no processo de ensino e aprendizagem em Matemática.

A História da Matemática surge como uma importante tendência no processo de ensino e aprendizagem de Matemática, uma vez que proporciona um ensino mais dinâmico, profundo e com forte caráter motivador, ao analisar-se sua evolução e descobertas e as relações existentes entre o passado e como a mesma é utilizada atualmente após a modernização de tais conceitos.

Após a realização das atividades os discentes mostraram maior interesse e aceitação com relação à Trigonometria, evidenciando que este recurso tornou o processo de ensino e aprendizagem mais interativo, construtivo e participativo, uma vez que os alunos foram instigados a pesquisar, a explorar e interpretar conceitos Trigonométricos.

Assim, considera-se que os objetivos foram alcançados e que esta abordagem pode contribuir para se desfazer a ideia de que a Matemática é inatingível e para poucos, e reforçando sua natureza humana, tornando-a compreensível para os alunos e evidenciada pela sua utilização no dia a dia.

\section{Referências}

BORTOLI, Gladis. Um Olhar Histórico nas Aulas de Trigonometria: Possibilidades de uma Prática Pedagógica Investigativa. 2012. Dissertação (Mestrado Profissional em Ensino de Ciências Exatas) - Centro Universitário Univates, Lajeado, 2012.

BRASIL. Parâmetros curriculares nacionais: matemática. Secretaria de Educação Fundamental. Brasília, MEC/SEF, 1998.

BRITO, Silvio Luiz Martins; BAYER, Arno. O uso da História no ensino da Matemática e a opinião dos professores de Matemática do Ensino Médio da $2^{\mathrm{a}} \mathrm{CRE}$ quanto ao uso desse recurso. Revista Acta Scientiae, Canoas, v. 9, n. 1, p. 41-62, 2007. 
Maria Mailâne Vieira da Silva, Deisiane Linhares Lima e Maria José Araújo Souza

História da Matemática e atividades com o teodolito: contribuições do PIBID/UVA para aprendizagem da Trigonometria

Disponível em:

<http://www.periodicos.ulbra.br/index.php/acta/article/download/95/88>. Acesso em: 15 de agosto de 2016.

JUSTINO. M. N. Pesquisa e recursos didáticos na formação e prática docentes. Marinice Natal Justino. Curitiba: Inter Saberes, 2013.

MENDES, Iran Abreu et al. História da Matemática em Atividades Didáticas. 2. ed. rev. São Paulo: Editora Livraria da Física, 2009.

MIGUEL, A. As potencialidades pedagógicas da História da Matemática em questão: argumentos reforçadores e questionadores. ZETETIKÉ, CEMPEM, FE/UNICEMP, v.5, n.8, Jul./Dez. 1997. p. 73-105

PALARMIDO, S. Trigonometria: Da História para a sala de aula. UFSCar/São Carlos: Departamento de Matemática, 2008. 82 p. Trabalho de Conclusão de Curso. 